\title{
Crystal structure of $\mathrm{Dy}_{2} \mathrm{Ga}_{1.8} \mathrm{Ge}_{5.2}$
}

\author{
Yaroslav TOKAYCHUK ${ }^{1}$, Taras DELENKO ${ }^{1}$, Roman GLADYSHEVSKII ${ }^{1}$ \\ ${ }^{1}$ Department of Inorganic Chemistry, Ivan Franko National University of Lviv, \\ Kyryla i Mefodiya St. 6, 79005 Lviv, Ukraine \\ * Corresponding author.Tel.: +380-32-2394506; e-mail: tokaychuk@mail.lviv.ua
}

Received December 9, 2013; accepted December 25, 2013; available on-line August 30, 2014

\begin{abstract}
A new ternary intermetallic compound, $D y_{2} \mathrm{Ga}_{1.8} \mathrm{Ge}_{5.2}$, was synthesized and its crystal structure determined from X-ray powder diffraction data: structure type $\mathrm{Sm}_{2}\left(\mathrm{Ga}_{0.26} \mathrm{Ge}_{0.74}\right)_{7}$, Pearson symbol $o S 80-8$, space group Cmce, $a=8.3284(6), b=8.0320(6), c=20.9167(15) \AA, Z=8$. The structure type $\operatorname{Sm}_{2}\left(G_{0.26} G_{0} e_{0.74}\right)_{7}$ is closely related to the type $\mathrm{Ce}_{2}\left(\mathrm{Ga}_{0.1} \mathrm{Ge}_{0.9}\right)_{7}$. Both types are vacancy derivatives of the structure type $\mathrm{SmNiGe}_{3}$, which is a linear intergrowth of layers characteristic of the structure types $\mathrm{BaAl}_{4}, \mathrm{AlB}_{2}$, and $\alpha-\mathrm{Po}$. In the structure of $\mathrm{Dy}_{2} \mathrm{Ga}_{1.8} \mathrm{Ge}_{5.2}$ every second square antiprism in the $\mathrm{BaAl}_{4}$-type slabs is vacant and the $\mathrm{Ga} / \mathrm{Ge}$ atoms centering the remaining antiprisms are subjected to displacement disorder modeled by a split site.
\end{abstract}

Dysprosium / Gallium / Germanium / X-ray powder diffraction / Crystal structure

\section{Introduction}

The crystal structure of the ternary compound $\mathrm{Ce}_{2}\left(\mathrm{Ga}_{0.1} \mathrm{Ge}_{0.9}\right)_{7}$ (own structure type, Pearson symbol oS72, space group Cmce, $a=8.6373, b=8.2697$, $c=21.451 \AA$ ) was solved from X-ray single-crystal diffraction data in 1989 [1]. At $600^{\circ} \mathrm{C}$ this compound has a certain homogeneity range, which can be described by the formula $\mathrm{Ce}_{2} \mathrm{Ga}_{2.24-0.91} \mathrm{Ge}_{4.76-6.09}$ [2]. Ternary compounds isotypic to $\mathrm{Ce}_{2}\left(\mathrm{Ga}_{0.1} \mathrm{Ge}_{0.9}\right)_{7}$ have been reported in other $R-\mathrm{Ga}-\mathrm{Ge}$ systems $(R=\mathrm{Y}, \mathrm{Pr}$, $\mathrm{Nd}, \mathrm{Gd}, \mathrm{Tb}$ ) [2-4]. Atomic coordinates were refined for $\mathrm{Y}_{2} \mathrm{Ga}_{0.34} \mathrm{Ge}_{6.66}(a=8.242, b=7.964, c=20.72 \AA)$ [3] and $\mathrm{Tb}_{2} \mathrm{Ga}_{1.82} \mathrm{Ge}_{5.18} \quad(a=8.2790, \quad b=7.9946$, $c=20.787 \AA$ ) [4], whereas for the other compounds the structure type was assigned based on X-ray diffraction phase analysis. Later the crystal structure of the ternary compound $\mathrm{Sm}_{2} \mathrm{Ga}_{1.8-0.9} \mathrm{Ge}_{5.2-6.1}$ was determined from $\mathrm{X}$-ray powder diffraction data for the composition $\mathrm{Sm}_{2} \mathrm{Ga}_{1.8} \mathrm{Ge}_{5.2}$ [5]. It defines a closely related structure type $\left(\mathrm{Sm}_{2}\left(\mathrm{Ga}_{0.26} \mathrm{Ge}_{0.74}\right)_{7}\right.$, Pearson symbol $o S 80-8$, space group Cmce, $a=8.4622$, $b=8.1534, c=21.1243 \AA$ ), which differs from the former by the splitting of one of the 8-fold sites occupied by $\mathrm{Ga} / \mathrm{Ge}$ atoms in $\mathrm{Ce}_{2}\left(\mathrm{Ga}_{0.1} \mathrm{Ge}_{0.9}\right)_{7}$ into a site in Wyckoff position $16 \mathrm{~g}$.

The aim of the present work was to determine the crystal structure of the new ternary compound $\mathrm{Dy}_{2}\left(\mathrm{Ga}_{x} \mathrm{Ge}_{1-x}\right)_{7}$, which was found during studies of the phase equilibria in the ternary system Dy-Ga-Ge at $600^{\circ} \mathrm{C}$.

\section{Experimental}

An alloy of nominal composition $\mathrm{Dy}_{22} \mathrm{Ga}_{20} \mathrm{Ge}_{58}$ was synthesized from high-purity metals (Dy $\geq 99.9$ wt.\%, $\mathrm{Ga} \geq 99.99$ wt.\%, Ge $\geq 99.999$ wt.\%) by arc melting in a water-cooled copper crucible under a purified argon atmosphere, using a tungsten electrode. To achieve good homogeneity, the sample was melted twice. After the synthesis the alloy was wrapped into tantalum foil, sealed in a quartz ampoule under vacuum and annealed at $600^{\circ} \mathrm{C}$ for $720 \mathrm{~h}$. Finally the ampoule with the sample was quenched into cold water. The weight loss, which was controlled at all stages of the synthesis, did not exceed $1 \%$ of the total mass, which was approximately $1 \mathrm{~g}$.

Phase analysis was carried out using the WinXPOW program package [6] on an X-ray powder diffraction pattern recorded on a STOE Stadi P diffractometer equipped with a linear position-

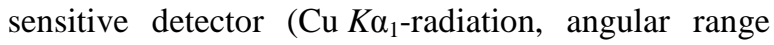
$4^{\circ} \leq 2 \theta \leq 110^{\circ}$, step $0.015^{\circ}$ ). The crystal structure of the ternary compound $\mathrm{Dy}_{2}\left(\mathrm{Ga}_{x} \mathrm{Ge}_{1-x}\right)_{7}$ was refined by the Rietveld method as included in the FullProf Suite program package [7], starting from the atom coordinates of the structure type $\mathrm{Ce}_{2}\left(\mathrm{Ga}_{0.1} \mathrm{Ge}_{0.9}\right)_{7}$ [1]. Due to the similarity of the atomic scattering factors of $\mathrm{Ga}$ and $\mathrm{Ge}$, the $\mathrm{Ga} / \mathrm{Ge}$ positions were assumed to be occupied by a mixture of $\mathrm{Ga}$ and $\mathrm{Ge}$ atoms in the ratio given by the nominal composition. In spite of the relatively good profile fit obtained by using as model the structure type $\mathrm{Ce}_{2}\left(\mathrm{Ga}_{0.1} \mathrm{Ge}_{0.9}\right)_{7}$, the values of the 
isotropic displacement parameters suggested disorder on one of the six sites occupied by $\mathrm{Ga} / \mathrm{Ge}$ atoms. Better values were obtained considering splitting of this site, initially located in Wyckoff position $8 f$, into a half-occupied site in Wyckoff position 16g. The resulting model corresponds to the structure type $\mathrm{Sm}_{2}\left(\mathrm{Ga}_{0.26} \mathrm{Ge}_{0.74}\right)_{7}$ [5]. The refined distance between neighboring positions of the split site was $0.57(2) \AA$. In the final cycles of the refinement an overall isotropic displacement parameter was refined for the positions occupied by $\mathrm{Ga} / \mathrm{Ge}$ atoms. Small amounts (4.5 wt.\% from the Rietveld refinement) of elementary Ge (structure type C (diamond), space group $F d-3 m, a=5.6542(5) \AA$ ) were found in the $\mathrm{Dy}_{22} \mathrm{Ga}_{20} \mathrm{Ge}_{58}$ sample, in agreement with the slight deviation from the Dy: $(\mathrm{Ga}, \mathrm{Ge})$ ratio 2:7. One scale factor and one cell parameter were refined for the admixture phase, while the profile parameters were constrained to be equal to those of the main phase. Finally, in total 33 parameters were allowed to vary: $2 \theta$ shift (with $\sin (2 \theta)$ dependence sample transparency coefficient), two scale factors, four cell parameters, six profile parameters (pseudo-Voigt profile), 17 positional parameters, two atomic displacement parameters, and one texture parameter. The background was defined using a Fourier filtering technique. The fit between the experimental and calculated X-ray powder diffraction patterns for the sample of nominal composition $\mathrm{Dy}_{22} \mathrm{Ga}_{20} \mathrm{Ge}_{58}$ is shown in Fig. 1. Experimental details and crystallographic data for the individual phases are listed in Table 1.

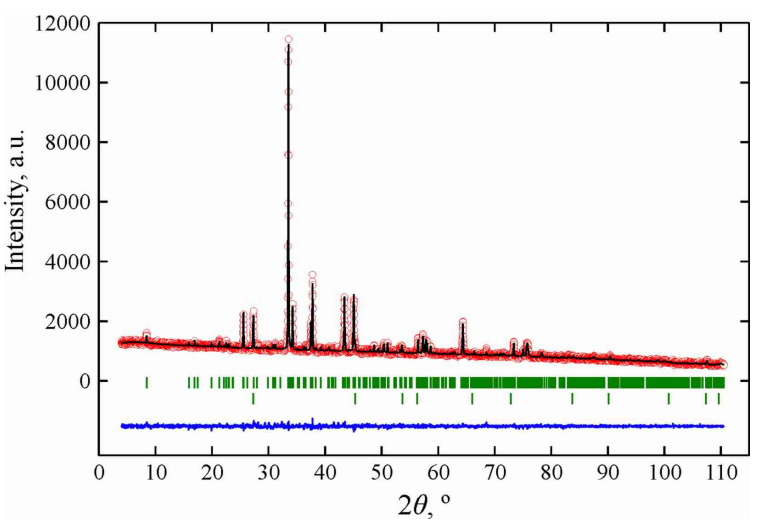

Fig. 1 Experimental (circles), calculated (continuous line) and difference between experimental and calculated (bottom) X-ray powder diffraction patterns for the sample $\mathrm{Dy}_{22} \mathrm{Ga}_{20} \mathrm{Ge}_{58}\left(\mathrm{Cu} \mathrm{K \alpha _{1 } \text { -radiation} ) . ~ V e r t i c a l ~ b a r s ~}\right.$ indicate the positions of the reflections of $\mathrm{Dy}_{2} \mathrm{Ga}_{1.8} \mathrm{Ge}_{5.2}$ and $\mathrm{Ge}$.

\section{Results and discussion}

The crystal structure of the ternary compound $\mathrm{Dy}_{2} \mathrm{Ga}_{1.8} \mathrm{Ge}_{5.2}$ belongs to the orthorhombic structure type $\mathrm{Sm}_{2}\left(\mathrm{Ga}_{0.26} \mathrm{Ge}_{0.74}\right)_{7}$. The positional coordinates and isotropic displacement parameters obtained from the Rietveld refinement are listed in Table 2. The structure contains one site occupied by Dy atoms and six sites occupied by $\mathrm{Ga}$ and $\mathrm{Ge}$ atoms.

Table 1 Experimental details and crystallographic data for the individual phases in the sample $\mathrm{Dy}_{22} \mathrm{Ga}_{20} \mathrm{Ge}_{58}$.

\begin{tabular}{|c|c|c|c|}
\hline \multicolumn{2}{|l|}{ Phase } & $\mathrm{Dy}_{2} \mathrm{Ga}_{1.8} \mathrm{Ge}_{5.2}$ & $\mathrm{Ge}$ \\
\hline \multicolumn{2}{|l|}{ Content, wt.\% } & $95.5(10)$ & $4.5(1)$ \\
\hline \multicolumn{2}{|l|}{ Structure type } & $\mathrm{Sm}_{2}\left(\mathrm{Ga}_{0.26} \mathrm{Ge}_{0.74}\right)_{7}$ & $\mathrm{C}$ (diamond) \\
\hline \multicolumn{2}{|l|}{ Pearson symbol } & oS $80-8$ & $c F 8$ \\
\hline \multicolumn{2}{|l|}{ Space group } & Cmce (\#64) & $F d-3 m(\# 227)$ \\
\hline \multirow[t]{3}{*}{ Cell parameters: } & $a, \AA$ & $8.3284(6)$ & $5.6542(5)$ \\
\hline & $b, \AA$ & $8.0320(6)$ & - \\
\hline & $c, \AA$ & $20.9167(15)$ & - \\
\hline \multicolumn{2}{|l|}{ Cell volume $V, \AA^{3}$} & $1399.19(17)$ & $180.77(3)$ \\
\hline \multicolumn{2}{|c|}{ Number of formula units in the cell $Z$} & 8 & 8 \\
\hline \multicolumn{2}{|l|}{ Density $D_{\mathrm{X}}, \mathrm{g} \mathrm{cm}^{-3}$} & 7.861 & 5.335 \\
\hline \multicolumn{2}{|c|}{ Preferred orientation: value / [direction] } & $0.898(6) /[110]$ & - \\
\hline \multirow[t]{2}{*}{ Reliability factors: } & $R_{\mathrm{B}}$ & 0.1050 & 0.0963 \\
\hline & $R_{F}$ & 0.1750 & 0.1040 \\
\hline \multirow[t]{3}{*}{ Profile parameters } & $U$ & \multicolumn{2}{|c|}{$0.005(5)$} \\
\hline & $V$ & \multicolumn{2}{|c|}{$0.014(5)$} \\
\hline & $W$ & \multicolumn{2}{|c|}{$0.0063(10)$} \\
\hline \multicolumn{2}{|l|}{ Shape parameter } & \multicolumn{2}{|c|}{$0.43(5)$} \\
\hline \multicolumn{2}{|c|}{ Asymmetry parameters } & \multicolumn{2}{|c|}{$0.103(8), 0.0245(18)$} \\
\hline \multirow[t]{3}{*}{ Reliability factors: } & $R_{\mathrm{p}}$ & \multicolumn{2}{|c|}{0.0276} \\
\hline & $R_{\mathrm{wp}}$ & \multicolumn{2}{|c|}{0.0358} \\
\hline & $\chi^{2}$ & \multicolumn{2}{|c|}{1.24} \\
\hline
\end{tabular}


As mentioned above, a peculiarity of the structure is the splitting of one of the $\mathrm{Ga} / \mathrm{Ge}(M)$ sites. The small $M$ atoms form an infinite three-dimensional framework containing layers of empty $M_{8}$ cubes and zigzag chains running along [010] (Fig. 2). The layers of cubes and the zigzag chains are interconnected along the crystallographic direction [001] via $\mathrm{Ga} / \mathrm{Ge}$ atoms from the split site $M 1$. One of the faces of the $M_{8}$ cubes is enlarged and rather rhomb-like. Site $M 1$ is split along the longer diagonal of this face, tending to achieve a four-bonded state instead of the five-bonded one in the idealized ordered structure. For the ternary compound $\mathrm{Sm}_{2} \mathrm{Ga}_{1.8} \mathrm{Ge}_{5.2}$, the following model was proposed for the distribution of the $\mathrm{Ga}$ and $\mathrm{Ge}$ atoms: the $M_{8}$ cubes are formed by $\mathrm{Ge}$ atoms, while site $M 1$ contains large amounts of $\mathrm{Ga}$, which stabilize the $M_{8+1}$ fragments [5].

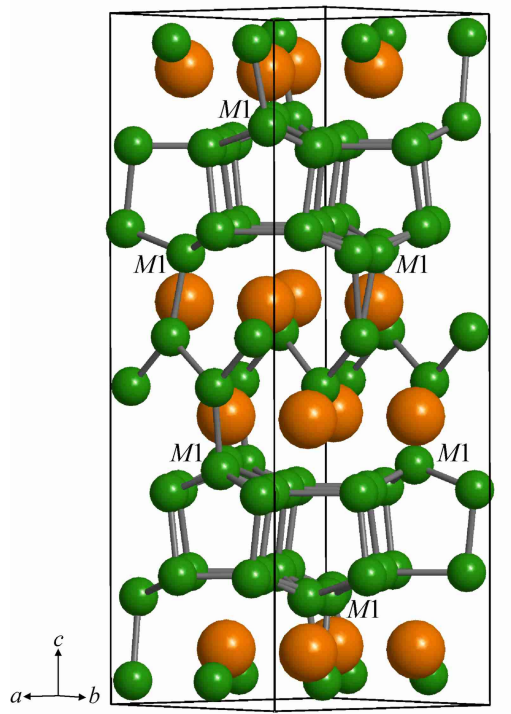

Fig. 2 Unit cell content of the compound $\mathrm{Dy}_{2} \mathrm{Ga}_{1.8} \mathrm{Ge}_{5.2}$, emphasizing the $\mathrm{Ga} / \mathrm{Ge}$ framework.

Selected interatomic distances, coordination numbers and coordination polyhedra in the structure of $\mathrm{Dy}_{2} \mathrm{Ga}_{1.8} \mathrm{Ge}_{5.2}$ are presented in Table. 3. The polyhedra around the Dy atoms have 18 vertexes ( $\left.\underline{\mathrm{Dy}} M_{12} \mathrm{Dy}_{6}\right)$ and can be described as pentagonal prisms $M_{10}$ with two additional $M$ and six additional Dy atoms. The $M$ sites have coordination numbers $8(M 2, M 3, M 5, M 6)$ and 9 (M1, M4). The corresponding polyhedra are: a square antiprism $\mathrm{Dy}_{4} M_{4}$ with one additional $M$ atom for $M 1$, trigonal prisms $\mathrm{Dy}_{2} M_{4}$ with two additional $M$ atoms for $M 2, M 5$, and $M 6$, a trigonal prism $\mathrm{Dy}_{6}$ with two additional $M$ atoms for $M 3$, and a trigonal prism $\mathrm{Dy}_{6}$ with three additional $M$ atoms for $M 4$. Like for $\mathrm{Sm}_{2} \mathrm{Ga}_{1.8} \mathrm{Ge}_{5.2}$, as a consequence of the splitting of site $M 1$ the distances to the two neighboring $M 2$ atoms have considerably different lengths (2.32 and $2.85 \AA$ for Sm, 2.17 and $2.70 \AA$ for Dy). The coordination polyhedron of site $M 4$ is similar to the polyhedra of the $\mathrm{Ga} / \mathrm{Ge}$ sites in the structures of the recently reported $\mathrm{AlB}_{2^{-}}$and $\alpha-\mathrm{ThSi}_{2}$-type phases in the system Dy-Ga-Ge at $600^{\circ} \mathrm{C}$, namely $\mathrm{DyGa}_{2-1.55} \mathrm{Ge}_{0-0.45}$ and $\mathrm{DyGa}_{1.4} \mathrm{Ge}_{0.6}$ [8]. It is difficult to draw any conclusions concerning possible ordering of $\mathrm{Ga}$ and $\mathrm{Ge}$ atoms from the analysis of the structure, but it seems reasonable to believe that $\mathrm{Ga}$ is mainly concentrated on site $M 1$, as suggested for $\mathrm{Sm}_{2} \mathrm{Ga}_{1.8} \mathrm{Ge}_{5.2}$ in [5].

The structure types $\mathrm{Sm}_{2}\left(\mathrm{Ga}_{0.26} \mathrm{Ge}_{0.74}\right)_{7}$ and $\mathrm{Ce}_{2}\left(\mathrm{Ga}_{0.1} \mathrm{Ge}_{0.9}\right)_{7}$ are vacancy derivatives of the structure type $\mathrm{SmNiGe}_{3}$ (oS20, Cmmm, $a=4.102, b=21.657$, $c=4.092 \AA$ ) [9]. The latter belongs to a homologous series of structures formed by linear intergrowth of slabs characteristic of the simple structure types $\mathrm{BaAl}_{4}$, $\mathrm{AlB}_{2}$, and $\alpha$-Po $[5,10,11]$. The defect $\mathrm{BaAl}_{4}$-type slabs in $\mathrm{Dy}_{2} \mathrm{Ga}_{1.8} \mathrm{Ge}_{5.2}$ contain $M 1$-centered square antiprisms alternating with empty square antiprisms. The $\mathrm{AlB}_{2}-$ type fragments are formed by trigonal prisms of Dy atoms centered by $\mathrm{Ga} / \mathrm{Ge}$ atoms from site $M 4$, and the $\alpha$-Po-type fragments are made from empty $M_{8}$ cubes. The ordered arrangement of vacancies in the $\mathrm{BaAl}_{4}$ type slabs results in doubling of the two short translation periods as compared with the structure of $\mathrm{SmNiGe}_{3}$. The intergrowth of slabs along [001] of the pseudo-tetragonal cell in $\mathrm{Dy}_{2} \mathrm{Ga}_{1.8} \mathrm{Ge}_{5.2}$ is shown in Fig. 3. A monoclinic vacancy derivative of $\mathrm{SmNiGe}_{3}$, which also forms in ternary $R-\mathrm{Ga}-\mathrm{Ge}$ systems [12], was first refined on $\mathrm{La}_{2} \mathrm{AlGe}_{6}(m S 36, C 2 / m, a=8.373$, $\left.b=8.833, \quad c=10.887 \AA, \quad \beta=101.34^{\circ}\right) \quad[13] . \quad$ It is interesting that three of the closely related structure types mentioned above, namely $\mathrm{Ce}_{2}\left(\mathrm{Ga}_{0.1} \mathrm{Ge}_{0.9}\right)_{7}$, $\mathrm{SmNiGe}_{3}$, and $\mathrm{La}_{2} \mathrm{AlGe}_{6}$, were found to coexist at the same temperature $\left(600^{\circ} \mathrm{C}\right)$ in the system $\mathrm{Y}-\mathrm{Ga}-\mathrm{Ge}[3]$.

Table 2 Positional coordinates and isotropic displacement parameters for the compound $\mathrm{Dy}_{2} \mathrm{Ga}_{1.8} \mathrm{Ge}_{5.2}$ (structure type $\mathrm{Sm}_{2}\left(\mathrm{Ga}_{0.26} \mathrm{Ge}_{0.74}\right)_{7}$, oS80-8, Cmce).

\begin{tabular}{c|c|c|c|c|c}
\hline Site & Wyckoff position & $x$ & $y$ & $z$ & $B_{\text {iso }}, \AA^{2}$ \\
\hline Dy & $16 g$ & $0.2504(6)$ & $0.3721(19)$ & $0.08098(10)$ & $0.42(8)$ \\
$M 1^{\mathrm{a}, \mathrm{b}}$ & $16 g$ & $0.0341(17)$ & $0.1158(19)$ & $0.1522(6)$ & $1.95(10)$ \\
$M 2^{\mathrm{a}}$ & $16 g$ & $0.2758(9)$ & $0.119(2)$ & $0.1908(2)$ & $1.95(10)$ \\
$M 3^{\mathrm{a}}$ & $8 f$ & 0 & $0.128(3)$ & $0.4602(8)$ & $1.95(10)$ \\
$M 4^{\mathrm{a}}$ & $8 f$ & 0 & $0.132(2)$ & $0.0335(8)$ & $1.95(10))$ \\
$M 5^{\mathrm{a}}$ & $8 f$ & 0 & $0.352(2)$ & $0.3054(8)$ & $1.95(10)$ \\
$M 6^{\mathrm{a}}$ & $8 f$ & 0 & $0.385(3)$ & $0.1880(7)$ & $1.95(10)$ \\
\hline
\end{tabular}

${ }^{\mathrm{a}} M=0.26 \mathrm{Ga}+0.74 \mathrm{Ge} ;{ }^{\mathrm{b}}$ Occ. $=0.5$. 
Table 3 Interatomic distances $(\delta)$, coordination numbers $(\mathrm{CN})$, and coordination polyhedra in the structure of the compound $\mathrm{Dy}_{2} \mathrm{Ga}_{1.8} \mathrm{Ge}_{5.2}$ (structure type $\mathrm{Sm}_{2}\left(\mathrm{Ga}_{0.26} \mathrm{Ge}_{0.74}\right)_{7}, o S 80-8$, Cmce).

\begin{tabular}{|c|c|c|c|c|}
\hline \multicolumn{2}{|c|}{ Atoms $^{\text {a }}$} & $\delta, \AA$ & $\mathrm{CN}$ & Polyhedron \\
\hline Dy & $\begin{array}{l}-1 M 1 \\
-1 M 3 \\
-1 M 4 \\
-1 M 2 \\
-1 M 3 \\
-1 M 6 \\
-1 M 2 \\
-1 M 4 \\
-1 M 1 \\
-1 M 5 \\
-1 M 4 \\
-1 M 3 \\
-1 \mathrm{Dy} \\
-1 \mathrm{Dy} \\
-2 \mathrm{Dy} \\
-1 \mathrm{Dy} \\
-1 \mathrm{Dy}\end{array}$ & $\begin{array}{c}2.945(16)(3.411(16))^{b} \\
2.985(18) \\
3.008(14) \\
3.043(13) \\
3.051(19) \\
3.061(12) \\
3.072(14) \\
3.110(14) \\
3.114(17)(3.474(16)) \\
3.161(13) \\
3.171(14) \\
3.276(14) \\
3.915(8) \\
3.962(8) \\
4.02(15) \\
4.157(8) \\
4.171(8)\end{array}$ & 18 & Dy \\
\hline$M 1$ & $\begin{array}{l}-1 M 2 \\
-1 M 5 \\
-1 M 6 \\
-1 M 4 \\
-1 M 2 \\
-1 \mathrm{Dy} \\
-1 \mathrm{Dy} \\
-1 \mathrm{Dy} \\
-1 \mathrm{Dy}\end{array}$ & $\begin{array}{c}2.169(16) \\
2.31(2) \\
2.31(3) \\
2.50(2) \\
2.704(16) \\
2.945(16) \\
3.114(17) \\
3.411(16) \\
3.474(16)\end{array}$ & 9 & \\
\hline$M 2$ & $\begin{array}{l}-1 M 1 \\
-1 M 2 \\
-1 M 5 \\
-1 M 6 \\
-1 \mathrm{Dy} \\
-1 \mathrm{Dy} \\
-1 M 6 \\
-1 M 5\end{array}$ & $\begin{array}{c}2.169(16)(2.704(16))^{b} \\
2.515(9) \\
2.634(17) \\
2.65(2) \\
3.043(13) \\
3.072(14) \\
3.14(2) \\
3.145(17) \\
\end{array}$ & 8 & $\underline{M 2}$ \\
\hline M3 & $\begin{array}{l}-1 M 4 \\
-1 M 3 \\
-2 \mathrm{Dy} \\
-2 \mathrm{Dy} \\
-2 \mathrm{Dy}\end{array}$ & $\begin{array}{c}2.463(3) \\
2.65(3) \\
2.985(18) \\
3.051(19) \\
3.276(14) \\
\end{array}$ & 8 & $\underline{M 3} \mathrm{Dy}_{6} M_{2}$ \\
\hline$M 4$ & $\begin{array}{l}-1 M 3 \\
-1 M 1 \\
-1 M 4 \\
-2 \mathrm{Dy} \\
-2 \mathrm{Dy} \\
-2 \mathrm{Dy}\end{array}$ & $\begin{array}{c}2.463(3) \\
2.50(2) \\
2.54(2) \\
3.008(14) \\
3.110(14) \\
3.171(14) \\
\end{array}$ & 9 & $M 4 \mathrm{Dy}_{6} M_{3}$ \\
\hline M5 & $\begin{array}{l}-1 M 1 \\
-1 M 6 \\
-2 M 2 \\
-2 M 2 \\
-2 \mathrm{Dy}\end{array}$ & $\begin{array}{c}2.31(2) \\
2.47(2) \\
2.634(17) \\
3.145(17) \\
3.161(13) \\
\end{array}$ & 8 & $\underline{M 5 \mathrm{Dy}_{2} M_{6}}$ \\
\hline M6 & $\begin{array}{l}-1 M 1 \\
-1 M 5 \\
-2 M 2 \\
-2 \mathrm{Dy} \\
-2 M 2\end{array}$ & $\begin{array}{c}2.31(3) \\
2.47(2) \\
2.65(2) \\
3.061(12) \\
3.14(2) \\
\end{array}$ & 8 & $M 6 \mathrm{Dy}_{2} M_{6}$ \\
\hline
\end{tabular}

${ }^{\mathrm{a}} M=0.26 \mathrm{Ga}+0.74 \mathrm{Ge},{ }^{\mathrm{b}}$ alternative interatomic distances due to splitting of site $M 1$ are indicated in italics. 


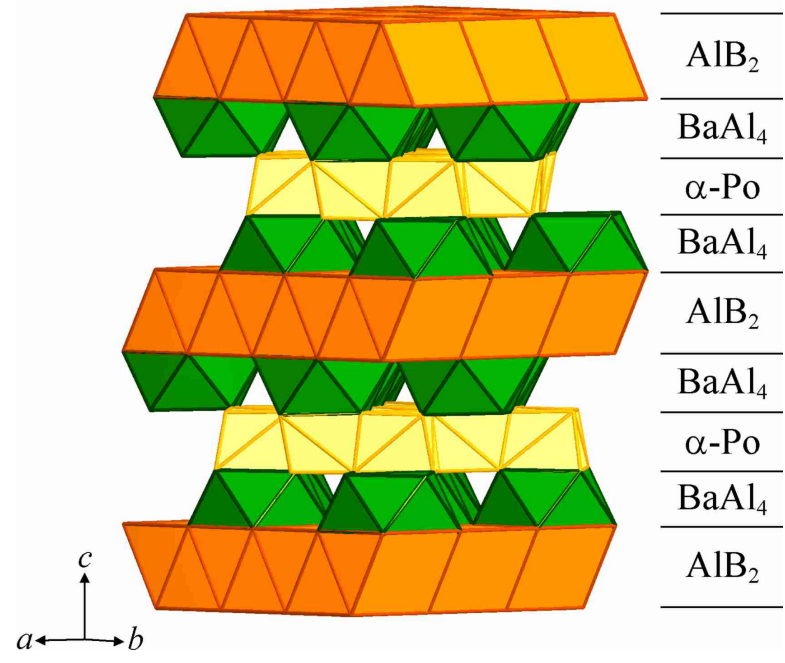

Fig. 3 Intergrowth of $\mathrm{AlB}_{2^{-}}, \alpha-\mathrm{Po}-$, and defect $\mathrm{BaAl}_{4}$-type slabs along [001] in the structure of $\mathrm{Dy}_{2} \mathrm{Ga}_{1.8} \mathrm{Ge}_{5.2}$.

\section{Conclusions}

The structure of the new ternary compound $\mathrm{Dy}_{2} \mathrm{Ga}_{1.8} \mathrm{Ge}_{5.2}$ was refined by the Rietveld method from X-ray powder diffraction data. The structure belongs to the structure type $\operatorname{Sm}_{2}\left(\mathrm{Ga}_{0.26} \mathrm{Ge}_{0.74}\right)_{7}$, which differs from the closely related type $\mathrm{Ce}_{2}\left(\mathrm{Ga}_{0.1} \mathrm{Ge}_{0.9}\right)_{7}$ by the splitting of one of the sites occupied by $\mathrm{Ga} / \mathrm{Ge}$ atoms. Both structure types may be considered as intergrowths of layers derived from the simple structure types $\mathrm{BaAl}_{4}, \mathrm{AlB}_{2}$, and $\alpha$-Po.

\section{Acknowledgements}

This work was supported by the Ministry of Education and Science of Ukraine under the grant No. 0112 U001280.

\section{References}

[1] Ya.P. Yarmolyuk, V.K. Pecharskii, I.A. Gryniv, O.I. Bodak, V.E. Zavodnik, Sov. Phys. Crystallogr. 34 (1989) 174-176.

[2] G. Effenberg (Ed.), Red Book. Constitutional Data and Phase Diagrams of Metallic Systems, Vol. 41, ASM International, Materials Park, Ohio, 1999, 2366 p.

[3] M.V. Speka, M.I. Zakharenko, V.Ya. Markiv, N.M. Belyavina, J. Alloys Compd. 367 (2004) 41-46.

[4] A.O. Fedorchuk, T.V. Dol'nikova, Coll. Abstr. XIV Ukr. Conf. Inorg. Chem., Kyiv, 1996, p. 179.

[5] Ya.O. Tokaychuk, Ya.E. Filinchuk, A.O. Fedorchuk, A.Yu. Kozlov, I.R. Mokra, J. Solid State Chem. 179 (2006) 1323-1329.

[6] WinXPow. Version 2.21, Stoe \& Cie GmbH, Darmstadt, 2007.

[7] J. Rodríguez-Carvajal, Commission on Powder Diffraction (IUCr), Newsletter 26 (2001) 12-19.

[8] Ya. Tokaychuk, T. Delenko, R. Gladyshevskii, Coll. Abstr. XIX Int. Sem. Phys. Chem. Solids Adv. Mater., Częstochowa, 2013, p. 121.

[9] O.I. Bodak, V.K. Pecharskii, O.Ya. Mrooz, V.E. Zavodnik, G.M. Vytvyts'ka, P.S. Salamakha, Dopov. Akad. Nauk Ukr. RSR, Ser. B (2) (1985) 36-38.

[10] E. Parthé, B. Chabot, K. Cenzual, Chimia 39 (1985) 164-174.

[11] E. Parthé, L. Gelato, B. Chabot, M. Penzo, K. Cenzual, R. Gladyshevskii, TYPIX Standardized Data and Crystal Chemical Characterization of Inorganic Structure Types, Gmelin Handbook of Inorganic and Organometallic Chemistry, Springer-Verlag, Berlin, 1993, Vol. 1, pp. 161-167.

[12] P. Villars, K. Cenzual (Eds.), Pearson's Crystal Data - Crystal Structure Database for Inorganic Compounds, Release 2013/14, ASM International, Materials Park, Ohio, 2013.

[13] J.T. Zhao, K. Cenzual, E. Parthé, Acta Crystallogr. C 47 (1991) 1777-1781. 